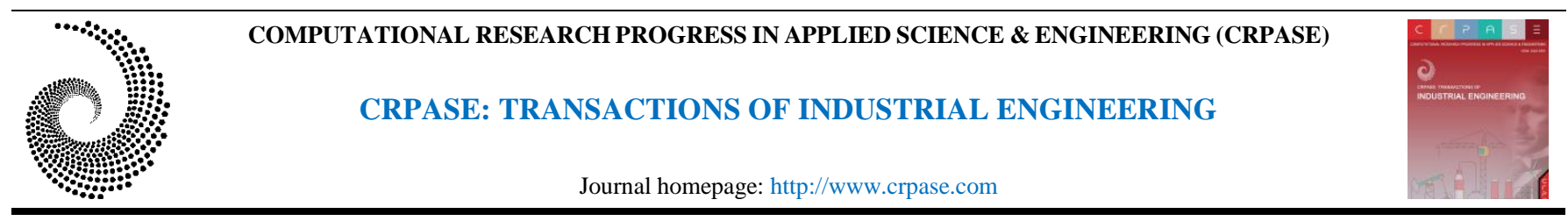

\title{
Multi-Objective TLBO and GWO-based Optimization for Placement of Renewable Energy Resources in Distribution System
}

\author{
Bibek KC ${ }^{1 *}$, Hassan Alkhwaildi ${ }^{2}$ \\ ${ }^{1}$ Department of Electrical and Computer Engineering, Southern Illinois University of Carbondale, USA \\ ${ }^{2}$ Department of Electrical and Computer Engineering, Southern Illinois University of Carbondale, USA
}

\begin{tabular}{ll}
\hline Keywords & Abstract \\
\cline { 2 - 3 } $\begin{array}{l}\text { Distributed Generation, } \\
\text { Fuzzy Decision, }\end{array}$ & $\begin{array}{l}\text { The use of renewable solar and wind resources as distributed generation sources in } \\
\text { distribution networks has been welcomed by network operators. In order to exploit the } \\
\text {-Gray Wolf Algorithm, } \\
\text { Multi-Objective }\end{array}$ \\
$\begin{array}{l}\text { Optimization, } \\
\text { Renewable Energy }\end{array}$ & $\begin{array}{l}\text { capacity should be determined optimally in the distribution network. In this paper, in order } \\
\text { to optimize the placement of solar panels and wind turbines in the distribution network with } \\
\text { the aim of reducing losses and improving reliability based on Energy Not Supplied } \\
\text { subscribers (ENS), a multi-objective evolutionary algorithm based on fuzzy decision } \\
\text { method, called the Multi-Objective Hybrid Training Learning Based Optimization-Grey } \\
\text { Wolf Optimizer (MOHTLBOGWO) proposed that has a High optimization speed and not } \\
\text { trapped at all in the optimal local. At first, the candidate buses are set for the installation of } \\
\text { renewable resources using the Loss Sensitivity Factor (LSF). Then the proposed method is } \\
\text { used to determine the location and optimal capacity of renewable resources through the } \\
\text { candidate bases. Proposed issues have been implemented in a single-objective and multi- } \\
\text { objective manner on a 33 bus IEEE radial distribution network. Also, in this paper, the effect } \\
\text { of distributing renewable resources on the characteristics of the distribution network is } \\
\text { evaluated. The results obtained from the proposed algorithm are compared with the results } \\
\text { of other algorithms to demonstrate the superiority of the proposed method in reducing losses, } \\
\text { improving reliability, and increasing the financial profit of the network. Simulation results } \\
\text { show the better performance of the proposed method in comparison with Teaching- } \\
\text { Learning Based Optimization (TLBO) and Grey Wolf Optimiser (GWO) methods and past } \\
\text { studies to achieve optimal results. Also, the results show that distributing of the capacity and } \\
\text { location of distributed renewable generation leads to a further reduction in losses and a better } \\
\text { improvement of the reliability criterion. }\end{array}$ \\
\hline
\end{tabular}

\section{Introduction}

The growing consumption of electric energy, mainly produced by burning fossil fuels, leads to various issues, such as environmental and financial issues. On the other hand, nearly $15 \%$ of active power is produced in large power plants $[1,2]$. This power is lost in transmission lines and distribution networks. Reducing power losses is one of the most interesting and most important issues in power system studies. There are several ways to minimize losses in power systems at the level of transmission and distribution networks [3]. DG placement is one of these methods. These methods have advantages such as improving reliability, improving the voltage profile, and reducing the power loss of the active. However, inappropriate placement and inappropriate DG planning can weaken the distribution

\footnotetext{
* Corresponding Author: Hassan Alkhwaildi

E-mail address: hassan.alkhwaildi@siu.edu
}

Received: 11 April 2021; Revised: 8 May 2021; Accepted: 15 June 2021

https://doi.org/10.52547/crpase.7.2.2356

Please cite this article as: B. KC, H. Alkhwaildi, Multi-Objective TLBO and GWO-based Optimization for Placement of Renewable Energy Resources in Distribution System, Computational Research Progress in Applied Science \& Engineering, CRPASE: Transactions of Industrial Engineering 7 (2021) 1-13, Article ID: 2356. 
network characteristics [4, 5]. Several studies have been conducted in the field of exploitation of distribution networks by optimal utilizing the dispersed generation sources in the distribution network. Classical, analytical, and meta-exploratory methods are the methods that have been proposed in this field. Classical methods are methods that can determine optimal response over a short period of time, but with increasing problem dimensions they cannot determine the optimal response. Analysis methods are methods that require additional computations and may not be able to achieve absolute optimal points [6]. Recently; Metaheuristic methods have been used to solve the problems of distribution network utilization. In [7], the Teachinglearning algorithm has been used and optimization has been achieved as a single-objective or two-objective. Placement of wind turbines and solar cells in the distribution network with the goal of reducing losses and improving the voltage stability conducted as a two-objective issue using the Particle Swarm Optimization algorithm [8, 9]. In [10, 11], in order to reduce the true power losses in distribution networks, the optimal placement of dispersed generation resources have been used in a combination and single-objective approach. In this study, a sensitivity analysis method was used to determine the best mode for locating dispersed generation sources and capacitors in the network. In [12], the optimal placement of renewable distributed generation sources is presented using evolutionary planning and its results are compared with the genetic method. The results show that, compared to the proposed method, the genetic algorithm finds the optimal problem at lower speeds. In [13], the locating of dispersed generation in distribution networks is provided by considering the voltage stability criteria. In this study, the genetic algorithm is used to find the best answer. In $[14,15]$, a new and high-efficiency algorithm is proposed using a firefly algorithm to determine the location and capacity of dispersed generation sources in an unbalanced distribution network in a single-objective optimization. The goal of the problem is to reduce network losses.

The use of Genetic Algorithm (GA) and Simulated Annealing algorithm for optimal allocation of DG in distribution network $[16,17]$ are presented in the form of single-objective optimization with the aim of reducing of losses. In [18, 19], the installation location of the DG is determined by the GA algorithm and its capacity is determined by the Particle Swarm Optimization (PSO). This work has been done on the basis of the weight coefficient method and is presented with the aim of reducing power losses, decreasing voltage oscillation of the bus and improving the voltage stability of the distribution network. In $[20,21]$, the Ant Colony Optimization (ACO) algorithm is proposed to determine the best installation location of the DG in the distribution network. This algorithm is presented in the form of single-objective optimization for reducing losses. Harmony Search algorithm (HS) is presented in [22] as an optimization method for solving this problem with the goal of reducing losses based on single-objective optimization. The Artificial Colony Bee (ABC) algorithm has been introduced in $[23,24]$ to determine the capacity, optimal power coefficient and DG installation location. This algorithm is presented in the form of single-objective optimization for reducing active losses. In [25], the Differential Evolution Algorithm (DEA) has been used to optimize single-objective DGs and achieve minimum losses. In [26], the Bacterial Foraging Optimization (BFO) Search Algorithm was used to optimize the planning of DG units in the distribution system with the goal of reducing losses, reducing operating costs, and improving voltage stability. This work is based on the weighting coefficient method and the multi-objective optimization form. The Imperialistic Competitive Algorithm (ICA) is used in [27] as a singleobjective optimization to minimize losses in the system. The Plant Growth Simulation Algorithm (PGSA) has been used in [28-30] to determine the unit capacity and the loss sensitivity factor in choosing optimal DG location. Firefly Algorithm (FA) is used in [21, 31] to optimize singleobjective DGs with the goal of reducing power losses. In [32, 33], Ant Lion Optimizer (ALO) algorithm is used to determine optimal location of installation and DG size based on renewable resources with the goal of reducing losses and improving the profiles and voltage stability in a multiobjective optimization based on weight coefficient method. In [34], the optimal placement of wind turbines in the distribution network is proposed using Cuckoo Search Algorithm (CSA) in a single-objective optimization with the goal of reducing power losses. In [35, 36], the locating of wind turbines and solar panels is proposed to reduce power losses and improve voltage stability using PSO algorithm based on multi-objective optimization and weight coefficient method.

As mentioned in most of the previous studies, the problem of positioning is presented as single or twoobjective optimization with the goal of reducing losses and improving the voltage profile, based on the weight coefficients method. In order to achieve a more accurate and realistic exploitation of the distribution network, the problem of the location of distributed generation should be considered as a multi-objective. One of the best ways for solving multiobjective problems is the use of Pareto levels to determine the optimal answer, which in this paper focuses on it and presents a multi-objective hybrid algorithm. On the other hand, the placement of renewable resources from the perspective of reliability, and considering the network failure rate and energy not-supplied network, has been less investigated. In this paper, these concepts are considered. In this paper, the proposed method is based on the combination of Teaching-learning and gray wolfs algorithms The Teaching-learning algorithm was presented in 2012 [37] and the high convergence rate and the lack of control parameters were the features of this method. The gray wolf method is presented in 2014 [38] and has been greatly welcomed to solve the power engineering optimization problems. This method has features such as high convergence speed, high computational power, fast and large searches and Avoid Local Optimal. Therefore, in this paper, in order to locating solar panels and wind turbines in a 33-buses radial standard distribution network and reducing losses and improving reliability, Utilizing the benefits of both methods, a multiobjective hybrid algorithm based on a fuzzy decision method called MOTLBOGWO is proposed. The main contribution of this article are following:

- Use of a new cumulative smart method called the HTLBOGWO method 
- $\quad$ Solve multi-objective problem of locating renewable resources based on fuzzy decision method in MOHTLBOGWO algorithm

- $\quad$ Study of the location of renewable energy sources from the perspective of reliability

- Assess the dispersal of location and capacity of renewable energy sources over network characteristics

The rest of this paper is organized as follows:

In Section 2, Loss Sensitivity Factor Formulation is described for determining the candidate buses for the installation of renewable energy sources. In Section 3, the problem formulation including optimization target function and problem constraints is presented. In Section 4, the proposed algorithm, the fuzzy decision method and implementation of the proposed method in problem solving described. In Section 5, the simulation results are presented and the conclusions are presented in Section 6.

\section{Loss Sensitivity Factor}

In this study, the Loss-Sensitivity Factor (LSF) is presented to show buses that are sensitive to losses [39, 40]. Also, using this factor can reduce the search area and the time of the optimization process. In other words, the buses that are in trouble for losses are identified by this factor, and thus instead of searching all the network buses for the installation of dispersed generation by the optimization method, the search area is limited to these buses, thereby the time of the calculations is reduced. For a transmission line ' $L$ ' connected between the buses "i" and "k", as shown in Figure 1, the active power losses on this line are defined by RI2, defined as Eq. (1) [32, 39].

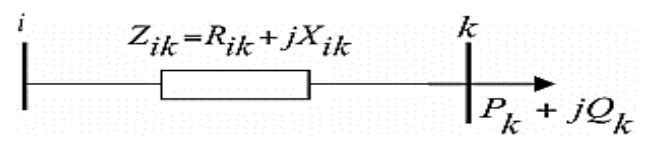

Figure 1. Distribution Network Equivalent Circuit [32]

$P_{i k-l o s s}=\frac{\left(P_{k}^{2}+Q_{k}^{2}\right) R_{i k}}{\left(V_{k}\right)^{2}}$

The LSF can be calculated as follows [41]:

$\frac{\partial \mathrm{P}_{\mathrm{ik}-\text { loss }}}{\partial \mathrm{Q}_{\mathrm{k}}}=\frac{2 \mathrm{Q}_{\mathrm{k}} \mathrm{R}_{\mathrm{ik}}}{\left(\mathrm{V}_{\mathrm{k}}\right)^{2}}$

The normalized voltage is obtained by dividing the voltage in the base conditions by $0.95[32,39]$. Buses whose their voltages are less than 1.01 can be considered as the candidate bass for DG installation. It's worth noting that LSFs introduce a sequence of buses for the installation of DG.

\section{Problem Formulation}

In this study, multi-objective optimization of location and capacity of solar panels and wind turbines in the distribution network using the MOHTLBOGWO hybrid algorithm is proposed to reduce losses and improve reliability. In order to achieve Pareto set levels, Problem optimization variables, the optimal location and capacity of dispersed wind and solar generation sources are determined using intelligent singleobjective optimization (using the HTLBOGWO method) as well as multi-objective based on decision-making fuzzybased approach.

\subsection{Objective Function}

In this study, the minimization of power losses and improvement of Reliability is considered as an objective function and is described below.

\section{- Line loss}

Total network losses are equal to the losses of all network lines. To calculate network losses, you must first get the current of lines. To calculate the current of lines, it is also necessary to solve the load distribution problem and obtain the voltage of the buses [42]. By calculating the buses voltages, the line currents and network losses are calculated as follows:

$$
\begin{gathered}
I_{k}=\frac{V_{i}-V_{j}}{R_{k}+j X_{k}} \\
P_{\text {loss }}=\sum_{k=1}^{N_{b}} R_{k} I_{k}{ }^{2}
\end{gathered}
$$

where $\mathrm{k}$ is between the buses $\mathrm{i}$ and $\mathrm{j}$. Rk and $\mathrm{Xk}$ are the resistance and reactance of the $\mathrm{k}$-th line, and $\mathrm{Nb}$ is the number of grid lines.

\section{- Reliability}

Reliability indicators are distribution system reliability assessment factors that were first introduced by the IEEE in 1998 to evaluate the distribution system. Basic reliability indicators are three load point indicators, a) The average rate of breakdown, b) the average withdrawal, and (c) the annual withdrawal period. A radial distribution system includes a set of series equipment including lines, brackets, fuses, and disconnected switches, and so on. A subsystem connected to the load point of a system requires that all equipment between it and the supply point be in operation. Therefore, the principle of serial systems can be considered directly for these systems as follows.

$$
\begin{aligned}
& \lambda_{p}=\sum_{i=1}^{n} \lambda_{i} \\
& u_{p}=\sum_{i=1}^{n} \lambda_{i} r_{i} \\
& r_{p}=\frac{u_{p}}{\lambda_{p}}=\frac{\sum_{i=1}^{n} \lambda_{i} r_{i}}{\sum_{i=1}^{n} \lambda_{i}}
\end{aligned}
$$


In the above equation, $\mathrm{n}$ is represent the number of outage events affecting load point $\mathrm{p}, \lambda_{i}$ denotes Equipment failure rate I (failure/year) and ri is repair time equip I (hours). Based on the basic indices of the load point and energy consumption at load points, energy not-supplied (ENS) $(\mathrm{kWh} /$ year) is calculated as follows [43].

$$
E N S=\sum_{j=1}^{n l} L_{a(j)} u_{j}
$$

where, $n l$ represents the total number of load points, the unavailability of the load point $j$ (hours/year), and the average load connected at the load point $j(\mathrm{~kW})$.

\subsection{Constraints}

In solving this optimization problem, a series of equal and unequal constraints is considered, which is expressed in sequence.

\section{- Equilibrium power equations}

The sum of the algebraic input and output power in the distribution system should be equal to:

$$
\begin{aligned}
& \mathrm{P}_{\text {Swing }}+\sum_{\mathrm{i}=1}^{\mathrm{N}_{\mathrm{DG}}} \mathrm{P}_{\mathrm{DG}}(\mathrm{i})=\sum_{\mathrm{i}=1}^{\mathrm{L}} \mathrm{P}_{\text {Lineloss }}(\mathrm{i})+\sum_{\mathrm{q}=1}^{\mathrm{N}} \mathrm{Pd}(\mathrm{q}) \\
& \mathrm{Q}_{\text {Swing }}+\sum_{\mathrm{i}=1}^{\mathrm{N}_{\mathrm{DG}}} \mathrm{Q}_{\mathrm{DG}}(\mathrm{i})=\sum_{\mathrm{i}=1}^{\mathrm{L}} \mathrm{Q}_{\text {Lineloss }}(\mathrm{i})+\sum_{\mathrm{q}=1}^{\mathrm{N}} \mathrm{Qd}(\mathrm{q})
\end{aligned}
$$

\section{- Voltage constraint}

The value of the voltage in each bus should be between a minimum and a maximum value as follows:

$$
\mathrm{V}_{\min } \leq\left|\mathrm{V}_{\mathrm{i}}\right| \leq \mathrm{V}_{\max }
$$

In the above relation, $\mathrm{Vmin}$ and $\mathrm{Vmax}$ are considered to be 0.95 and 1.05 p.u respectively [32].

\section{- Constraints on the production of DG}

To prevent reverse power flow, the installed DG capacity in the network is limited as follows, which should not exceed the power supplied by the post [32].

$$
\begin{aligned}
& \sum_{\mathrm{i}=1}^{\mathrm{N}_{\mathrm{DG}}} \mathrm{P}_{\mathrm{DG}}(\mathrm{i}) \leq \frac{3}{4} \times\left[\sum_{\mathrm{i}=1}^{\mathrm{L}} \mathrm{P}_{\text {Lineloss }}(\mathrm{i})+\sum_{\mathrm{q}=1}^{\mathrm{N}} \mathrm{Pd}(\mathrm{q})\right] \\
& \sum_{\mathrm{i}=1}^{\mathrm{N}_{\mathrm{DG}}} \mathrm{Q}_{\mathrm{DG}}(\mathrm{i}) \leq \frac{3}{4} \times\left[\sum_{\mathrm{i}=1}^{\mathrm{L}} \mathrm{Q}_{\text {Lineloss }}(\mathrm{i})+\sum_{\mathrm{q}=1}^{\mathrm{N}} \mathrm{Qd}(\mathrm{q})\right]
\end{aligned}
$$

On the other hand, DGs themselves have the minimum and the maximum production capacity is as follows [43].

$$
\begin{aligned}
& \mathrm{P}_{\mathrm{DG}}^{\min } \leq \mathrm{P}_{\mathrm{DG}}(\mathrm{i}) \leq \mathrm{P}_{\mathrm{DG}}^{\max } \\
& \mathrm{Q}_{\mathrm{DG}}^{\min } \leq \mathrm{Q}_{\mathrm{DG}}(\mathrm{i}) \leq \mathrm{Q}_{\mathrm{DG}}^{\max }
\end{aligned}
$$

\section{- Line capacity constraints}

The Complex power transmission of each line should be less than the nominal value given in the following equation.

$\mathrm{S}_{\mathrm{Li}} \leq \mathrm{S}_{\mathrm{Li}(\text { rated })}$

\section{Overview of Proposed Algorithm}

\subsection{TLBO}

The TLBO algorithm is a smart optimization method that was introduced by Rao [15] based on the influence of teacher to students to increase scientific level of class. This method is based on this principle that the teacher tries to close class level to himself and students, in addition to exploit the teacher's knowledge with regard to other classmates, use their knowledge to increase level of them. Because of the teacher can't bring level of individual students to himself, so tries to increase the average level of whole class and evaluates the class level based on the exams and students' scores. The mathematical expression of this approach is that first the population of problem variables (teacher and students) are defined randomly. All of these populations are compared together by the objective function and set of variables with best solution are considered as the teacher. This approach is divided into two phases: teacher phase and student phase.

\section{- Teacher phase}

In this step teacher tries to bring class average to himself. But since it is very difficult, teacher tries to increase class average from $M i$ to $M \_n e w$. Each set of problem variables are updated based on the difference of these two values. Difference of these two values can be saved by the parameter Diff_Mean as follows:

$$
\operatorname{Diff}_{-} \mathrm{Mean}_{i}=r_{i}\left(M_{-} n e w-T_{f} M_{i}\right)
$$

Where $T_{f}$ is the teacher parameter that is selected randomly between 1 and 2. The $r_{i}$ is a random number between 0 and 1 . Using the follow equation each set of variables are updated.

$$
X_{n e w, i}=X_{\text {old }, i}+\text { Diff__ean }_{i}
$$

\section{- $\quad$ Student phase}

Students in addition to teacher's knowledge, benefit from each other's knowledge. The mathematical expression of this approach is that in each step and in each repetition each set of variable (student) selects one of students randomly. For example student $i$ selects student $j$ and this $i$ is opposite of $j$. If the student $j$ has more knowledge respects to student $i$ then the student $i$ updates his status based on the following equation:

$X_{n e w, i}=X_{o l d, i}+r_{i}\left(X_{i}-X_{j}\right)$

The student status is varied as follows: 


$$
X_{\text {new }, i}=X_{\text {old }, i}+r_{i}\left(X_{j}-X_{i}\right)
$$

After the all students changed their status, their level is evaluated by the objective function. Under these conditions the best student is compared with the teacher of previous step and if a better result has, is replaced with previous iteration teacher. This process is continued to obtain convergence conditions.

\section{2. $G W O$}

One of the population-based intelligent and evolutionary algorithms is the Gray Wolf algorithm (GWO) which was first announced by Mir-Jalili in 2014 [38]. In this algorithm, the performance and behaviour of gray wolfs for hunting is simulated. Figure 2 shows that parameters such as $\alpha, \beta, \delta$, and $\omega$ represent the leaders of the group so that $\alpha$ directs the group as leader of the group and has important decisions about hunting, resting place and so on. The second group of leadership belongs to $\beta$. In addition to being able to help $\alpha$ due to having a good decision, $\beta$ members are also the best substitutes for the $\alpha$ wolfs when they are old or dead; $\omega$ but is at the bottom of this group. They are the last wolves that are allowed to eat. The other group members that are not $\alpha$, $\beta$ and $\omega$ are called $\delta[38]$.

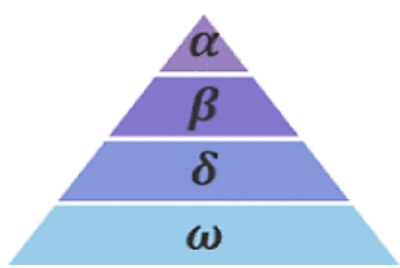

Figure 2. Leader hierarchy in gray wolves group

The principles of GWO function are as follows:

- Investigating, pursuing and following the hunt;

- Pursuing, sieging and harassing the hunt until it stops; and

- Attacking to the hunt.

In the simulation of the GWO, $\alpha$ is considered as a top answer. After that, the next two responses after $\alpha$ are considered $\beta$ and $\delta$. Finally, the rest answers are regarded $\omega$. To model a suitable situation that gray wolves encircle their hunt during hunting are shown as follows [38].

$\vec{D}=\left|\vec{C} \cdot \vec{X}_{P}(t)-\vec{X}(t)\right|$

$\vec{X}(t+1)=\vec{X}_{P}(t)-\vec{A} \vec{D}$

where t represents the repetition, $\vec{A}, \vec{C}$, and $\vec{X}_{P}$ indicate the coefficients vectors, the position of the bait and the gray wolf respectively. The coefficients vector is obtained from the following equation [38].

$$
\vec{A}=2 \vec{a} \vec{r}_{1}-\vec{a}
$$

$\vec{C}=2 \vec{r}_{2}$

where vectors of random numbers at a distance are shown by and that are selected from $[0,1]$ area and vector $\vec{a}$ decreases from 2 to 0 during repetitions.

According to the wolf ability due to finding and surrounding the hunt and in order to having a mathematical simulation of this kind of behaviour, it is assumed that the three top wolves in the group have more knowledge about the hunting place. By storing the position of the three above mentioned wolves, $\omega$ wolves have to change their location based on the position of the three top members of the group which can be expressed as follows [38]:

$$
\begin{aligned}
& \vec{D}_{\alpha}=\left|\vec{C}_{1} \vec{X}_{\alpha}-\vec{X}\right|, \vec{D}_{\beta}=\left|\vec{C}_{2} \vec{X}_{\beta}-\vec{X}\right|, \vec{D}_{\delta}=\left|\vec{C}_{3} \vec{X}_{\delta}-\vec{X}\right| \\
& \vec{X}_{1}=\vec{X}_{\alpha}-\vec{a}_{1} \vec{D}_{\alpha}, \vec{X}_{2}=\vec{X}_{\beta}-\vec{a}_{2} \vec{D}_{\beta}, \vec{X}_{3}=\vec{X}_{\delta}-\vec{a}_{3} \vec{D}_{\delta} \\
& \vec{X}(t+1)=\frac{\vec{X}_{1}+\vec{X}_{2}+\vec{X}_{3}}{3}
\end{aligned}
$$

\subsection{HTLBOGWO (TLRBO)}

The TLBO algorithm is a robust algorithm capable of solving engineering problems. However, a new phase has been added to this algorithm to increase the global and local search capability as well as track the optimal answer. This phase is due to the choice of first, second and third students as the best answers after the student phase. After selecting the top three students, the remaining students will learn from these three students. The process of selection students and their ranking is considered to be the ranking phase, which is called the TLRBO algorithm.

Since the ranking phase and follow up of the students and their learning from the top three students are very similar to the behaviour of the gray wolf algorithm, So in the formulation of TLRBO, method of selection the wolf-alpha, beta, and delta and the method of updating the location of the wolfs of Omega to follow up the top three wolves have been used. Therefore, the proposed algorithm will be a combination of the TLBO and GWO algorithms.

\subsection{HTLBOGWO (TLRBO) Multi-Objective Algorithm}

Multi-objective issues have multiple goals, which are mostly contradictory. The answer to these problems is a set of solutions called Pareto optimal solutions [44]. This set includes Pareto optimal solutions that represent the best balance between the objectives. Multi-objective optimization is considered as a minimization problem and formulated as follows [43]:

$$
\begin{aligned}
& \text { minimize: } \mathrm{F}(\overrightarrow{\mathrm{x}})=\left\{f_{1}(\overrightarrow{\mathrm{x}}), f_{2}(\overrightarrow{\mathrm{x}}), \ldots, f_{0}(\overrightarrow{\mathrm{x}}),\right\} \\
& \text { subject to: } \mathrm{g}_{i}(\overrightarrow{\mathrm{x}}) \geq 0, \mathrm{i}=1,2, \ldots, m \\
& \mathrm{~h}_{i}(\overrightarrow{\mathrm{x}})=0, \mathrm{i}=1,2, \ldots, p \\
& L_{i} \leq x_{i} \leq U_{i}
\end{aligned}
$$

where 0 represents the number of targets, $m$ denotes the number of inequality constraints and $\mathrm{p}$ is the number of 
equality constraints. $[\mathrm{Li}, \mathrm{Ui}]$ are the boundaries variable $\mathrm{i}$. Given the nature of the multi-objective problems, various solutions cannot be compared through mathematical relations operators. In this case, Pareto optimal parental concepts allow us to compare two solutions in a multiobjective search space [43].

Two key points in finding a suitable set of optimal Pareto solutions for the given problem are convergence and coverage. Convergence refers to the ability of a multiobjective algorithm to determine the exact approximation of Pareto's optimal solution. The coverage reflects the distribution of Pareto's optimal response along the objectives. Since many of the current multi-objective algorithms are deductive, coverage and the number of answers for decision-making after the optimization process are very important. The ultimate goal for a multi-objective optimizer is to find the exact approximation of the optimal Pareto correct solution (convergence) with uniform distribution (coverage) for all purposes.

To solve multi-objective problems using the MOHTLBOGWO algorithm, it first equipped to an archive to store and restores the best approximation of the optimal Pareto solution. The position updating of the search factors for MOHTLBOGWO is the same, but the student's position is selected from the archive. In order to find a suitable expansion for the Pareto optimal frontier, a place from the low-density Pareto optimal frontier, similarly for multiobjective particle swarm optimization algorithm (MOPSO) [45] is selected. To find the low-density area of Pareto optimal frontier, the search space should be divided. This is accomplished by finding the best and worst objectives of Pareto's optimal solution, the definition of the hyper-sphere to cover all the solution, and the division of the hyper-sphere into sub-hyper-sphere in each repetition. After the creation of the section, the choice is made by a roulette wheel mechanism with the following probability for each section proposed by Coello Coello [2].

$P_{i}=\frac{c}{N_{i}}$

where $c$ is a constant number greater than one, and $N i$ is the number of obtained Pareto's optimal response in the i-th section. This allows MOHTLBOGWO algorithm equations with higher probability to choose positions from low population sections.

\subsection{Fuzzy Decision Making}

The ultimate goal of a multi-objective optimization algorithm is to identify solving in the Pareto optimal set. However, identifying the entire Pareto optimal set is not possible due to its wide dimensions to prove the optimality, and therefore not recommended. Therefore, to investigate the feasibility of having Pareto optimal sets in multiple optimization problems, there is a practical approach. In the present study, a fuzzy approach is applied to select the best solution of the Pareto set. The j-objective function of a solution in Pareto set $\mathrm{fj}$ is defined by a membership function $\mathrm{j}$ as follows [46]:

$$
\mu_{j}=\left\{\begin{array}{ll}
1 & f_{j} \leq f_{j}^{\min } \\
\frac{f_{j}^{\max }-f_{j}}{f_{j}^{\max }-f_{j}^{\min }} & f_{j} \leq f_{j}^{\min } \\
0 & f_{j} \geq f_{j}^{\max }
\end{array}\right\}
$$

where $f_{j}^{\min }$ and $f_{j}^{\max }$ are the minimum and maximum values of the objective function $j$. For each $i$ solution, the membership function is calculated as follows [19]:

$\mu_{j}=\frac{\sum_{j=1}^{n} \mu_{j}^{i}}{\sum_{i=1}^{m} \sum_{j=1}^{n} \mu_{j}^{i}}$

where $n$ is the number of objective functions and $\mathrm{m}$ is the number of solutions. The answers have the maximum value of $\mu i$ for the best compromise answer.

\subsection{Implementation of MOHTLBOGWO}

The steps to implement the proposed method in problem solving are as follows:

- Step 1: Random generation of the initial population from the set of variables including the location of the installation and the capacity of solar and wind units as well as the power factor of wind turbines.

- $\quad$ Step 2: the value of the target function is calculated for each set of variables and the best set is selected in terms of the value of the objective function as the representative of the entire population.

- Step 3: Each set of variables is updated by the proposed algorithm, and if the new variables have better results, they will be replaced with the previous set.

- Step 4: if the condition for convergence does not exist, go to step 1. Otherwise, go to step 5.

- $\quad$ Step 5: Stop the algorithm.

\section{Simulation Results and Discussion}

\subsection{Testing System}

As shown in Figure 3, in this paper, the proposed method is implemented on the IEEE standard 33-buses radial network. In the 33-buses network, the total consumption of this network is $3720 \mathrm{~kW}$ and $2300 \mathrm{kVAR}$. The 33-buses Network has 37 branches. System information is presented in [47].

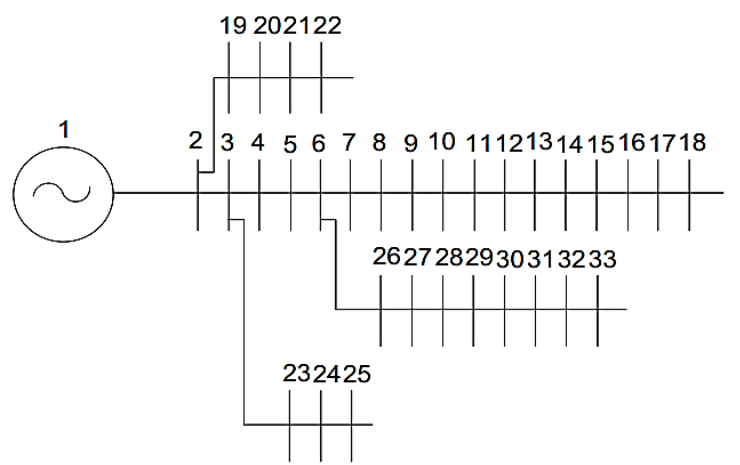

Figure 3. IEEE Standard Radial 33-buses Distribution Network 


\subsection{Simulation Strategies}

In this paper, the optimal placement of solar panels and wind turbines for the purpose of reducing losses and improving reliability indicators are presented using the proposed method HTLBOGWO. First, simulations were performed in a single-objective optimization. Then, multiobjective optimization was proposed based on fuzzy decision method and the results were compared and analyzed. In single-objective optimization, simulation results obtained from TLBO, GWO, and HTLBOGWO methods are evaluated based on indicators of loss reduction and energy not-supplied subscriber reduction (reliability improvement). In multi-objective optimization, the results of multiobjective methods MOGWO, MOTLBO and MOTLBOGWO are presented. In Figure 4, the LSF curve of the 33-buses network is presented. In this figure, the buses 6 , $28,29,30,9,10,13,8,27,31$ and 26 are based on the LSF curve considered as the candidate buses for installing wind turbines and solar panels Which are similar to Candida buses in reference [32].

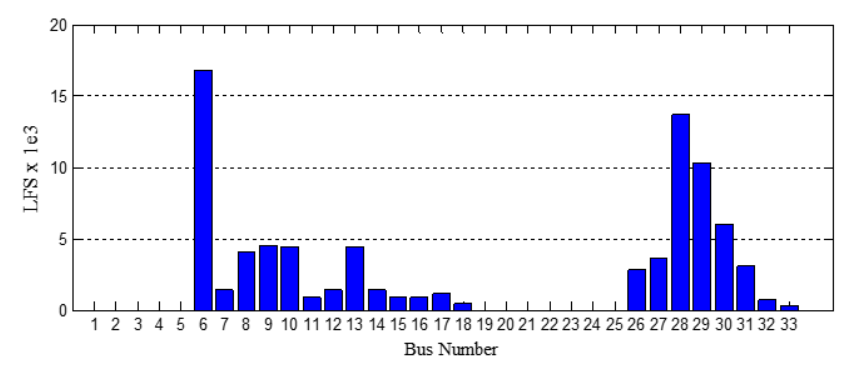

Figure 4. LSF curve of the 33-buses network

\subsection{Single-Objective Optimization Results}

In this section, the results of single-objective positioning of solar panels and wind turbines are presented for the purpose of reducing losses and reducing ENS for 1, 2 and 3 DGs 1 megawatts. In Table 1, the results are presented with the objective of reducing losses. In the positioning of 3 solar panels, the buses 13, 24 and 30 were selected for installation with a capacity of 996,938 and $852 \mathrm{~kW}$ respectively. The network losses before positioning were 202.68 kilowatts. After locating one, two, and three panels, this value has dropped to $127.28,86.55$ and $72.11 \mathrm{~kW}$, respectively. In locating of 3 wind turbines, the buses 30, 13 and 24 were selected for installation with a capacity of 997,1000 and 789 $\mathrm{kW}$ and with power factors $0.8659,0.8122$ and 0.8726 respectively. With locating 1, 2 and 3 wind turbines, the network losses dropped from 202.68 to $81.43,32.17$ and 13.68 kilowatts, respectively. With 1,2 and 3 wind turbines, the network losses dropped from 202.68 to $81.43,32.17$ and 13.68 kilowatts, respectively.

Also, the minimum voltage is also improved by the use of panels and turbines. The results also show that the ENS value before the locating of solar panels and wind turbines was 6.695 MW, and after locating 3 panels it reached 0.628 $\mathrm{MW}$, and after locating 3 turbines reached $0.671 \mathrm{MWh}$. The results show that the cost of network losses with the optimal locating of solar panels and wind turbines has decreased and financial benefits from loss reduction have increased. In addition, the results have shown that increasing the number of DGs has led to a further reduction in losses, reduction cost of losses, and ENS, as well as further increase in the minimum voltage and net profit of the network. The results show that the performance of wind turbines was better than solar panels in improving the distribution network characteristics. In other words, in terms of reduction of losses and ENS, as well as the improvement of minimum voltage, it achieves better results due to the injection of reactive power in addition to the active power to the distribution network.

Table 1. Optimal sizing DG's for 33 bus IEEE system (active power loss objective function)

\begin{tabular}{|c|c|c|c|c|}
\hline & \multicolumn{4}{|c|}{ Maximum Size 3MW (kW/pf/@ Bus) } \\
\hline & No PV & 1PV & $2 \mathrm{PV}$ & $3 \mathrm{PV}$ \\
\hline Power Losses $(\mathrm{kW})$ & 210.98 & 127.28 & 86.55 & 72.11 \\
\hline ENS (MWh/yr) & 6.695 & 4.158 & 1.923 & 0.628 \\
\hline Minimum Voltage (pu) & 0.91308 & 0.9285 & 0.9629 & 0.9667 \\
\hline Size and Location & -- & 1000/1@30 & $\begin{array}{l}\text { 893/1@10, } \\
\text { 1000/1@30 }\end{array}$ & $\begin{array}{l}\text { 996/1@13, } \\
938 / 1 @ 24, \\
852 / 1 @ 30\end{array}$ \\
\hline Total Size (kW) & -- & 1000 & 1893 & \\
\hline Losses Cost $(\$ / y r)$ & 110891 & 66899.8 & 45491.3 & 37903.5 \\
\hline \multirow[t]{2}{*}{ Net Saving $(\$ / y r)$} & -- & 43991.2 & 65399.7 & 72987.5 \\
\hline & No WT & 1WT & 2WT & $3 \mathrm{WT}$ \\
\hline Power Losses (kW) & 210.98 & 81.43 & 32.17 & 13.68 \\
\hline ENS (MWh/yr) & 6.695 & 4.158 & 2.233 & 0.640 \\
\hline Minimum Voltage (pu) & 0.91308 & 0.9360 & 0.9796 & 0.9892 \\
\hline Size and Location & -- & 1000/0.8011@30 & $\begin{array}{c}\text { 861/ 0.8742@10, } \\
\text { 1000/0.8091@30 }\end{array}$ & $\begin{array}{c}\text { 997/0.8659 @30, } \\
\text { 1000/0.8122@13, } \\
789 / 0.8726 @ 24\end{array}$ \\
\hline Total Size (kW) & -- & & & \\
\hline Losses Cost $(\$ / y r)$ & 110891 & 42801 & 16913.5 & 7191.6 \\
\hline Net Saving (\$/yr) & -- & 68090 & 93977.5 & 103699.4 \\
\hline
\end{tabular}


The convergence curve of the combined HTLBOGWO combination method, along with TLBO and GWO methods for single-objective optimization of solar panels and wind turbines with the goal of reducing losses for $3 \mathrm{DGs}$, is shown in Figure 5 and Figure 6, respectively. As can be seen, in locating solar panels and wind turbines, the HTLBOGWO method has less convergence fluctuations, and achieved a lower loss rate than the TLBO and GWO with a higher convergence rate and less repetition.

Single-objective optimization results with the goal of reducing losses using TLBO, GWO and HTLBOGWO methods for 3DG are presented in Table 2. As can be seen, the proposed method is better than other methods in terms of reducing losses, reducing cost of losses, reducing ENS, improving the minimum voltage and increasing the financial profit of the network.

Table 3 presents the results of single-objective positioning of solar panels and wind turbines with the goal of reducing ENS for 1, 2 and 3 DG 1 megawatts. As can be seen, with the locating of 1 and 2 solar panels, the network losses are decreasing, but in the positioning of the three panels, the losses compared to the positioning of the two turbines increased from 87.17 to 97.04 kilowatt, but in contrast to the positioning of the three panels, the ENS value was strongly Dropped to $0.0025 \mathrm{MWh}$. In the positioning of wind turbines, with increasing its number, the amount of losses decreased, the minimum network voltage increased and the amount of ENS decreased, so that it reached 0.002 MW in the positioning of 3 turbines. Also, with the optimal locating of turbines, the cost of losses is reduced and the amount of financial gain in the locating of the three turbines has a maximum value. This table also shows that wind turbines have a better effect on the characteristics of the distribution network than solar panels.

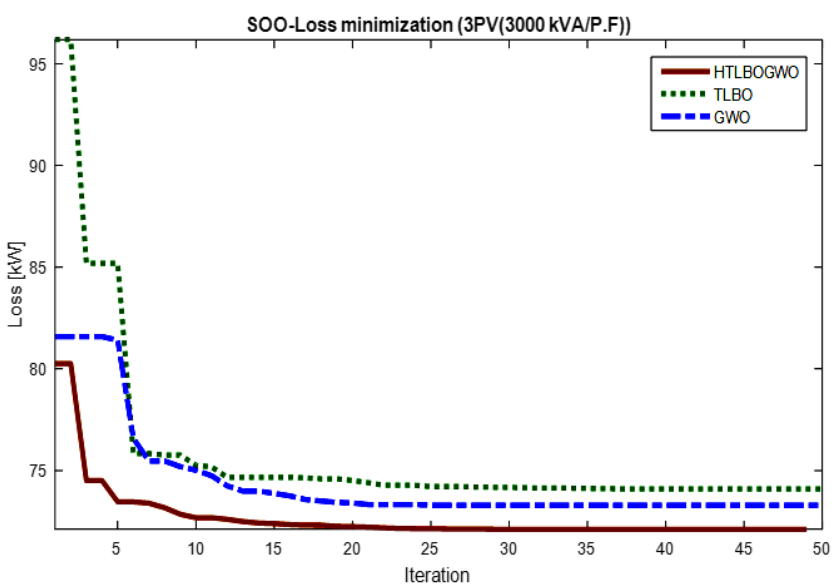

Figure 5. Convergence curve of different methods with the aim of reducing the losses in the $3 \mathrm{PV}$ positioning

Single-objective optimization results with the aim of reducing the ENS obtained from the HTLBOGWO method are presented in Table 4 and compared with the TLBO and GWO methods. The amount of losses by the proposed method was 97.04 kilowatts and the losses obtained from the TLBO and GWO methods were 101.25 and $103.17 \mathrm{~kW}$ respectively. Also, the amount of ENS by the proposed method, $0.025 \mathrm{MWh}$ and by TLBO and GWO methods were 0.048 and $0.044 \mathrm{MW}$, respectively, which indicates the superiority of the proposed method in solving the problem of positioning solar panels. Also, according to

Table 4, in the locating of solar panels and wind turbines, the HTLBOGWO method performed better than other methods in terms of reducing losses, reducing ENS, improving the minimum voltage and financial profit of the network.

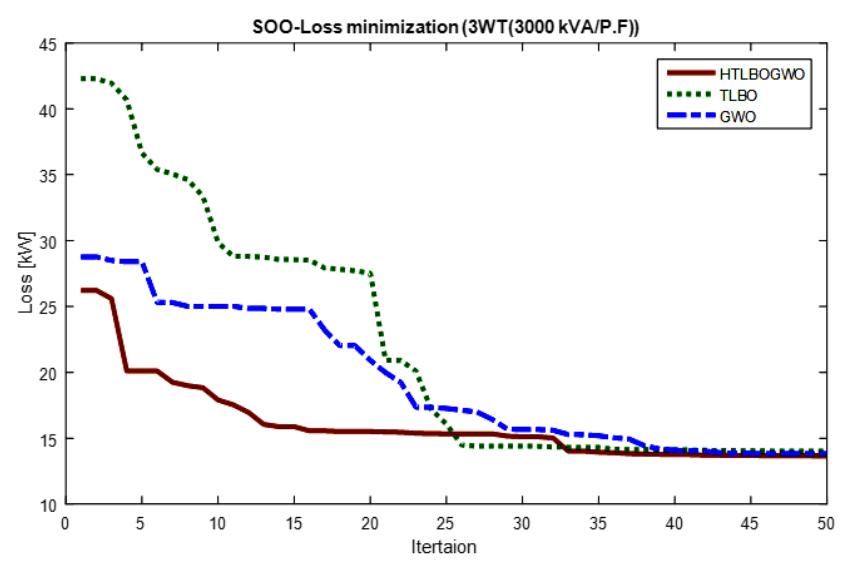

Figure 6. Convergence curve of different methods with the aim of reducing losses in the 3 WT positioning

\subsection{Assessment of the Renewable Resource Dispersion Effect}

In this section, the effect of dispersing the capacity of solar panels and wind turbines has been evaluated in problem solving. In other words, the effect of using a $3 \mathrm{MW} \mathrm{DG}$ with the use of three DGs with a capacity of $1 \mathrm{MW}$ on the power loss, reliability index, minimum network voltage, cost of losses and financial profit of the network has been evaluated. The results obtained in Table 5 and Table 6 are presented for the purpose of decreasing losses and decreasing the ENS in a single-objective optimization, respectively. As can be seen, when using three DGs with a capacity of $1 \mathrm{MW}$ instead of using a 3 MW DG The amount of network losses and ENS will be lower and the network obtaining the higher minimum voltage, more financial gain and reduce cost of losses. For example, according to Table 5, in dispersal conditions, the network losses decreased from 103.96 to $72.11 \mathrm{kV}$ and ENS values decreased from 4.379 to 0.628 megawatts / h. According to Table 6, under dispersal conditions, the amount of network losses decreased from 161.26 to 97.04 kilowatts and ENS values from decreased 0.11 to $0.025 \mathrm{MWh}$. The voltage profile curve of 33-buses network before locating and under dispersion conditions for solar panels and wind turbines is plotted in Figure 7. Also Figure 7 shows the voltage profile curve of 33-buses network before locating and under conditions where there is no dispersion condition. Figure 7 and Figure 8 showed that the distribution and distribution of power in the network buses leads to improvement of the network voltage profile. 
Table 2. Optimal sizing DG's for 33-bus IEEE system (active power loss objective function-algorithms comparison)

\begin{tabular}{|c|c|c|c|c|}
\hline & \multicolumn{4}{|c|}{ Maximum Size 3MW (kW/pf/@ Bus) } \\
\hline & No PV & TLBO & GWO & HTLBOGWO \\
\hline Power Losses (kW) & 210.98 & 74.10 & 73.29 & 72.11 \\
\hline ENS (MWh/yr) & 6.695 & 0.734 & 0.659 & 0.628 \\
\hline Minimum Voltage (pu) & 0.9130 & 0.9621 & 0.9648 & 0.9667 \\
\hline $\begin{array}{l}\text { Size and Location } \\
\text { Total Size }(\mathrm{kW})\end{array}$ & $\begin{array}{l}-- \\
--\end{array}$ & $\begin{array}{c}872(29), 858(13), 946 \\
\text { (24) }\end{array}$ & $\begin{array}{c}889 \text { (24), } 903 \text { (30), } 994 \\
(10)\end{array}$ & $\begin{array}{c}\text { 996/1@13,938/1@24, } \\
\text { 852/1@30 }\end{array}$ \\
\hline Losses Cost $(\$ / y r)$ & 110891 & 38949.0 & 38525.7 & 37903.5 \\
\hline \multirow[t]{2}{*}{ Net Saving (\$/yr) } & -- & 71942 & 72365.3 & 72987.5 \\
\hline & No WT & TLBO & GWO & HTLBOGWO \\
\hline Power Losses $(\mathrm{kW})$ & 210.98 & 14.02 & 13.82 & 13.68 \\
\hline ENS (kWh/yr) & 6.695 & 0.787 & 0.657 & 0.640 \\
\hline \multirow[t]{2}{*}{ Minimum Voltage (pu) } & 0.9130 & 0.9892 & 0.9891 & 0.9892 \\
\hline & & 972 (24) $0.8636,1000(30)$ & 962 (24) $0.8659,804(13)$ & $\begin{array}{c}\text { 997/0.8659 @ } 30, \\
1000 / 0.8122 @ 13,789 /\end{array}$ \\
\hline Size and Location & -- & $0.8011,760$ (13) 0.8299 & $0.8122,1000(30) 0.8726$ & 0.8726@24 \\
\hline Total Size (kW) & -- & & -- & -- \\
\hline Losses Cost $(\$ / y r)$ & 110891 & 7370.5 & 7267.1 & 7191.6 \\
\hline Net Saving (\$/yr) & -- & 103520.5 & 103623.9 & 103699.4 \\
\hline
\end{tabular}

Table 3. Optimal sizing DG's for 33 bus IEEE system (ENS objective function)

\begin{tabular}{ccccc}
\hline & \multicolumn{3}{c}{ Maximum Size 3MW $(\mathrm{kW} / \mathrm{pf} / @$ Bus $)$} \\
\hline & No PV & $1 \mathrm{PV}$ & $2 \mathrm{PV}$ & $3 \mathrm{PV}$ \\
\cline { 2 - 5 } Power Losses $(\mathrm{kW})$ & 210.98 & 129.47 & 87.17 & 97.04 \\
ENS $(\mathrm{kWh} / \mathrm{yr})$ & 6.695 & 3.502 & 0.965 & 0.035 \\
Minimum Voltage $(\mathrm{pu})$ & 0.9130 & 0.9319 & 0.9655 & 0.9705 \\
Size and Location & -- & $1000 / 1 @ 13$ & $1000 / 1 @ 30,1000 / 1 @ 13$ & $709 / 1 @ 30,810 / 1 @ 10$, \\
Total Size $(\mathrm{kW})$ & -- & & & $957 / 1 @ 13$ \\
Losses Cost $(\$ / \mathrm{yr})$ & 110891 & 68053.5 & 45819.5 & 51008.3 \\
Net Saving $(\$ / \mathrm{yr})$ & -- & 42837.5 & 65071.5 & 59882.7 \\
& No WT & $1 \mathrm{WT}$ & $2 \mathrm{WT}$ & $3 \mathrm{WT}$ \\
Power Losses $(\mathrm{kW})$ & 210.98 & 103.21 & 62.16 & 55.43 \\
ENS $(\mathrm{kWh} / \mathrm{yr})$ & 6.695 & 3.412 & 0.9630 & 0.011 \\
Minimum Voltage $(\mathrm{pu})$ & 0.9130 & 0.9385 & 0.9576 & 0.98248 \\
Size and Location & -- & $1000(10) 0.8237$ & $1000(30) 0.9480$, & $993(13) 0.8579,802(29)$ \\
Total Size $(\mathrm{kW})$ & -- & & $1000(10) 0.9981$ & $0.8427,762(30) 0.8209$ \\
Losses Cost $(\$ / \mathrm{yr})$ & 110891 & 54251.4 & 32671.6 & 29136.6 \\
Net Saving $(\$ / \mathrm{yr})$ & -- & 56639.6 & 78219.4 & 81754.4 \\
\hline
\end{tabular}

Table 4. Optimal sizing DG's for 33 bus IEEE system (ENS objective function-Algorithms comparison)

\begin{tabular}{|c|c|c|c|c|}
\hline & \multicolumn{4}{|c|}{ Maximum Size 3MW (kW/pf/@ Bus) } \\
\hline & No PV & TLBO & GWO & HTLBOGWO \\
\hline Power Losses (kW) & 210.98 & 101.25 & 103.17 & 97.04 \\
\hline ENS (kWh/yr) & 6.695 & 0.048 & 0.044 & 0.035 \\
\hline Minimum Voltage (pu) & 0.9130 & 0.9694 & 0.9677 & 0.9705 \\
\hline Size and Location & -- & $\begin{array}{c}986(9) \\
789(29) \\
1000(13)\end{array}$ & $\begin{array}{l}807(29), \\
830(13), \\
1000(10)\end{array}$ & $\begin{array}{l}709(30), \\
810(10), \\
957(13)\end{array}$ \\
\hline Total Size (kW) & -- & & & \\
\hline Losses Cost (\$/yr) & 110891 & 53217.5 & 54228.8 & 51008.3 \\
\hline Net Saving (\$/yr) & -- & 57673.5 & 56662.2 & 59882.7 \\
\hline & No WT & TLBO & GWO & HTLBOGWO \\
\hline Power Losses $(\mathrm{kW})$ & 210.98 & 58.17 & 59.61 & 55.43 \\
\hline ENS (kWh/yr) & 6.695 & 0.018 & 0.016 & 0.011 \\
\hline Minimum Voltage (pu) & 0.9130 & 0.9808 & 0.9800 & 0.98248 \\
\hline Size and Location & -- & $\begin{array}{c}893 \\
\text { (9) } 0.8760,762 \\
\text { (30) } 0.982 \\
1000 \\
\text { (13) } 0.9519\end{array}$ & $\begin{array}{c}652 \\
\text { (29) } 0.9660,978 \\
\text { (13) } 0.9465,920 \\
\text { (30) } 0.9824\end{array}$ & $\begin{array}{c}993 \\
\text { (13) } 0.8579,802 \\
\text { (29) } 0.8427,762 \\
\text { (30) } 0.8209\end{array}$ \\
\hline Total Size (kW) & -- & & & \\
\hline Losses Cost $(\$ / y r)$ & 110891 & 30577.0 & 31334.6 & 29136.6 \\
\hline Net Saving $(\$ / y r)$ & -- & 80314 & 79556.4 & 81754.4 \\
\hline
\end{tabular}


Table 5. Results of DGs distribufication (SOO-Loss minimization)

\begin{tabular}{|c|c|c|c|c|}
\hline \multirow[b]{2}{*}{ PV } & \multicolumn{4}{|c|}{ Maximum Size 3MW (kW/pf/@Bus) } \\
\hline & $\begin{array}{c}\text { 1DG (3000) } \\
(\mathrm{kVA} / \mathrm{P} . \mathrm{F})\end{array}$ & $\begin{array}{c}\text { 1DG (3000) } \\
(\mathrm{kVA} / \mathrm{P} . \mathrm{F}) \text { ALO [32] }\end{array}$ & $\begin{array}{c}\text { 1DG (3000) } \\
(\mathrm{kVA} / \mathrm{P} . \mathrm{F})[47]\end{array}$ & $\begin{array}{c}\text { 3DG (1000) } \\
(\mathrm{kVA} / \mathrm{P} . \mathrm{F})\end{array}$ \\
\hline Power Losses $(\mathrm{kW})$ & 101.96 & 103.053 & 118.96 & 72.11 \\
\hline Minimum Voltage (pu) & 0.9510 & 0.9503 & 0.9441 & 0.9667 \\
\hline Size and Location & 2585/1@29 & 2450/1@6 & 1857.5/1@8 & $\begin{array}{l}996 / 1 @ 13, \\
938 / 1 @ 24, \\
852 / 1 @ 30\end{array}$ \\
\hline Total Size $(\mathrm{kW})$ & & & & \\
\hline Losses Cost (\$/yr) & 53590.1 & 54164.6 & 62525.3 & 37903.5 \\
\hline Net Saving (\$/yr) & 57300.9 & 56726.4 & 44002.6 & 68624.7 \\
\hline WT & $\begin{array}{c}\text { 1DG (3000) } \\
(\mathrm{kVA} / \mathrm{P} . \mathrm{F})\end{array}$ & $\begin{array}{c}\text { 1DG (3000) } \\
(\mathrm{kVA} / \mathrm{P} . \mathrm{F}) \text { ALO [32] }\end{array}$ & $\begin{array}{c}\text { 1DG (3000) } \\
(\mathrm{kVA} / \mathrm{P} . \mathrm{F})[47]\end{array}$ & $\begin{array}{c}\text { 3DG (1000) } \\
(\mathrm{kVA} / \mathrm{P} . \mathrm{F})\end{array}$ \\
\hline Power Losses $(\mathrm{kW})$ & 61.36 & 71.75 & 82.78 & 13.68 \\
\hline ENS (kWh/yr) & 4.406 & -- & -- & 0.671 \\
\hline Size and Location & $2544(6) 0.8236$ & 2238.8 (18) 0.87 & $2265.2(8) 0.82$ & $\begin{array}{c}\text { 997/0.8659@30, } \\
1000 / 0.8122 \\
@ 13, \\
789 / 0.8726 @ 24\end{array}$ \\
\hline Total Size (kW) & & & & \\
\hline Losses Cost $(\$ / y r)$ & 32253.1 & 37711.8 & 43509.1 & 7191.6 \\
\hline Net Saving (\$/yr) & 78637.9 & 73179.3 & 63018.8 & 99336.6 \\
\hline
\end{tabular}

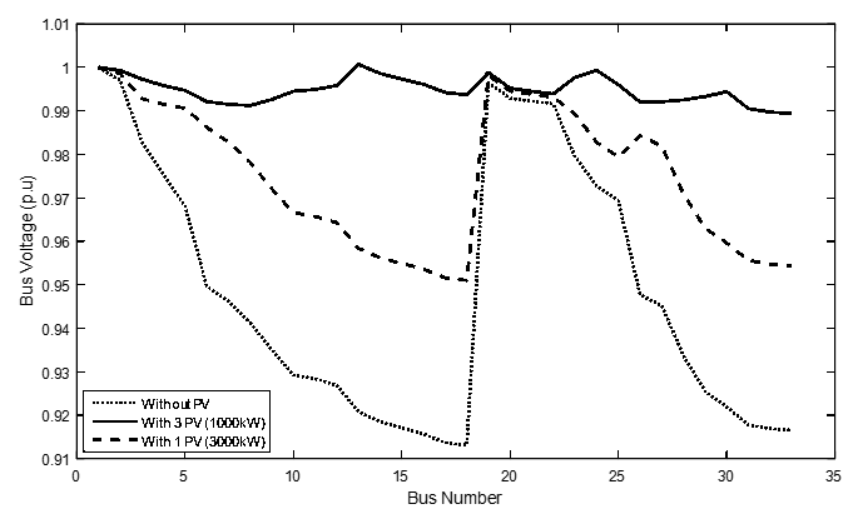

Figure 7. Network voltage profile of 33 buses before placing solar panels and under dispersion conditions

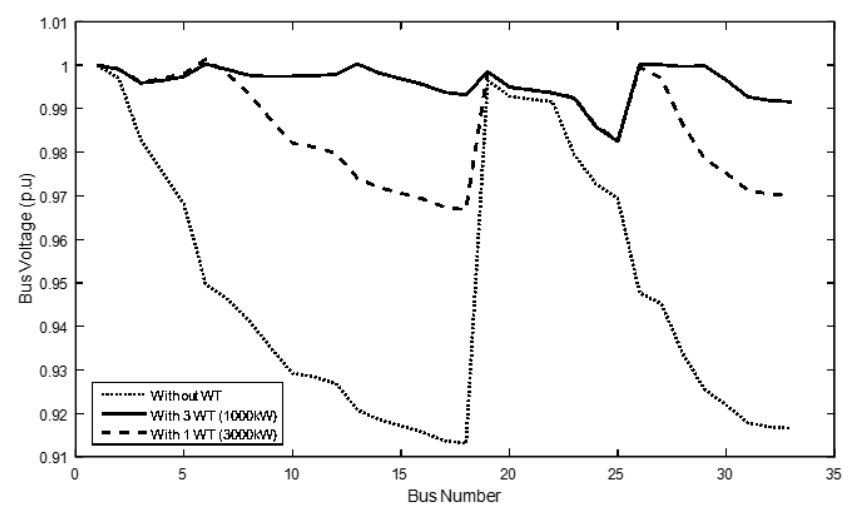

Figure 8. Network voltage profile of 33 buses before placing wind turbines and under dispersion conditions

\subsection{Multi-Objective Optimization Results}

In this section, multi-objective optimization of the locating of solar panels and wind turbines is presented based on the fuzzy decision approach using the HTLBOGWO method and the results are compared with the TLBO and GWO multi-objective methods. The Pareto optimal set of solutions for placement of 1 panel and 1 wind turbine with a capacity of $1 \mathrm{MW}$ is shown in Figure 9 and Figure 10, respectively. As shown in Figure 9, the MOHTLBOGWO method, in comparison with the MOTLBO and MOGWO response scattering, offers better results in terms of achieving an optimal response. Also, in the terms of achieving to lower losses, lower ENS, minimum voltage, lower cost of losses and higher financial profit, the proposed method performance was better than the other two methods. Also, according to Table 7 and Table 8 , in the multi-objective optimization, items such as the losses, ENS, the minimum voltage, the cost of losses, and the amount of financial gain are located between the single-objective values that aimed at reducing losses and reducing ENS. In other words, in the multi-objective optimization, there is a Compromise between the losses and ENS.

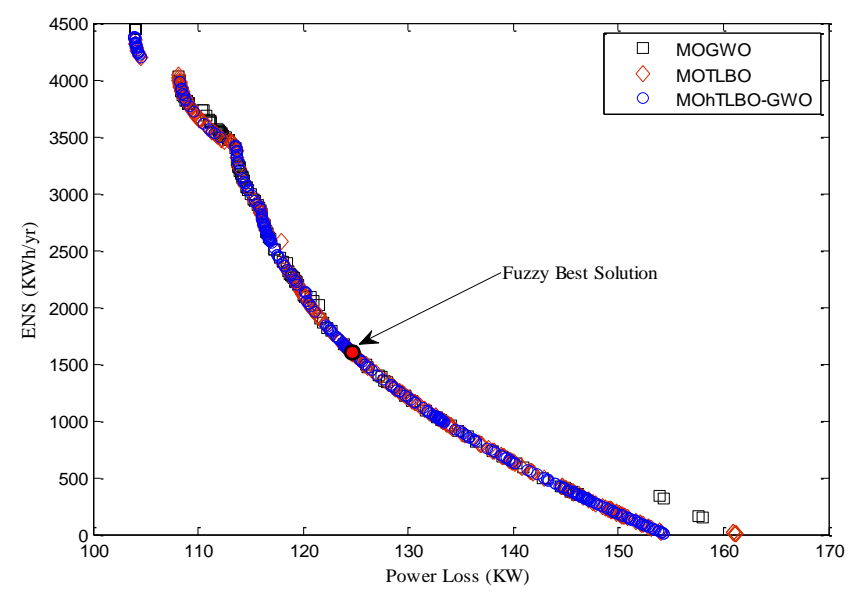

Figure 9. Pareto optimal answers set curve in the placement of the solar panels by various methods 


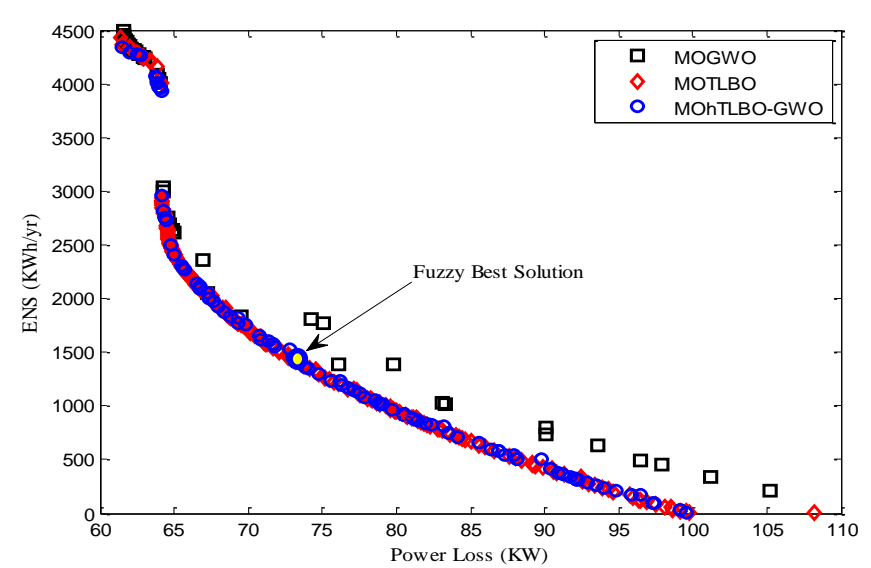

Figure 10. Pareto optimal answers set curve in the placement of the wind turbines by various methods

In Figure 11, the multi-objective positioning of both panels and turbines simultaneously is presented using various methods. The numerical results are also given in Table 9. The results show that the proposed MOTLBOGWO method offers better Pareto-optimal solution than other methods and has obtained the optimal solution with less dispersion. Also, according to Table 9, can be seen that the simultaneous use of 1 panel and 1 turbine instead of use one panel or one turbine, has led to a further reduction of losses and ENS, a further increase in the minimum voltage and net profit of the network.

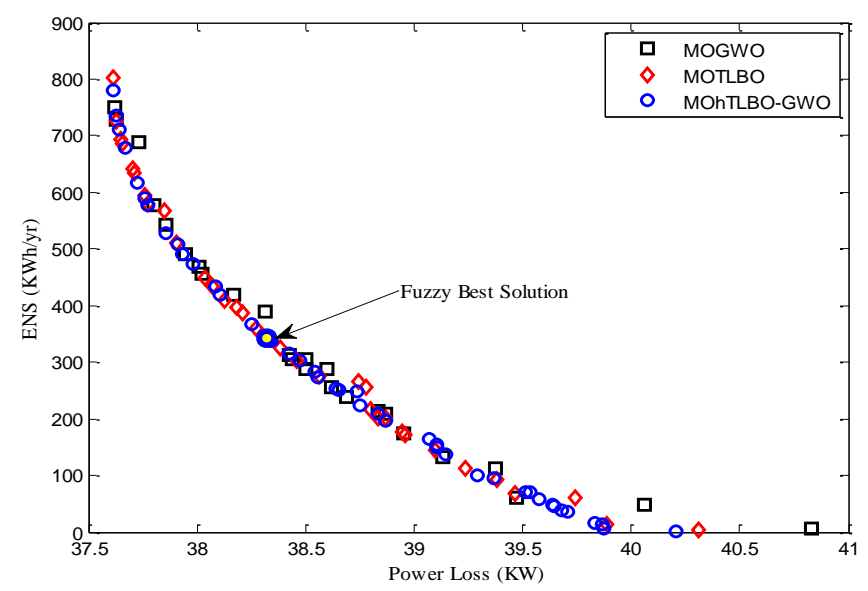

Figure 11. Pareto optimal answers set curve (PV + WT only with maximum capacity of 3 megawatts)

Table 6. Results of DGs distribufication (SOO-ENS minimization)

\begin{tabular}{|c|c|c|}
\hline & \multicolumn{2}{|c|}{ Maximum Size 3MW (kW/pf/@ Bus) } \\
\hline & 1DG (3000) & 3DG (1000) \\
\hline & $(\mathrm{kVA} / \mathrm{P} . \mathrm{F})$ & $(\mathrm{kVA} / \mathrm{P} . \mathrm{F})$ \\
\hline Power Losses (KW) & 161.26 & 97.04 \\
\hline ENS (kWh/yr) & 1.337 & 0.035 \\
\hline Minimum Voltage (pu) & 0.9466 & 0.9705 \\
\hline & $2097(10)$ & $709(30)$ \\
\hline Size and Location & & $810(10)$ \\
\hline & & $957(13)$ \\
\hline \multicolumn{3}{|l|}{ Total Size (kW) } \\
\hline Losses Cost $(\$ / y r)$ & 84761.3 & 51008.3 \\
\hline \multirow{3}{*}{ Net Saving (\$/yr) } & 26129.7 & 59882.7 \\
\hline & 1DG (3000) & 3DG (1000) \\
\hline & $(\mathrm{kVA} / \mathrm{P} . \mathrm{F})$ & $(\mathrm{kVA} / \mathrm{P} . \mathrm{F})$ \\
\hline Power Losses $(\mathrm{kW})$ & 100.09 & 55.43 \\
\hline ENS $(\mathrm{kWh} / \mathrm{yr})$ & 0.481 & 0.011 \\
\hline Minimum Voltage (pu) & 0.9564 & 0.98248 \\
\hline Size and Location & 2639 (13) 0.8729 & 993 (13) 0.8579, 802 (29) 0.8427, 762 \\
\hline Total Size $(\mathrm{kW})$ & & (30) 0.8209 \\
\hline Losses Cost (\$/yr) & 52611.4 & 29136.6 \\
\hline Net Saving $(\$ / y r)$ & 58279.6 & 81754.4 \\
\hline
\end{tabular}

Table 7. Fuzzy multi-objective results for $1 \mathrm{PV}$ placement

\begin{tabular}{ccccc}
\hline & \multicolumn{4}{c}{ Maximum Size 3MW (kW/pf/@ Bus) } \\
\cline { 2 - 5 } & No DG & $\begin{array}{c}\text { 1PV } \\
\text { (Loss objective) }\end{array}$ & 1PV & 1PV \\
(ENS objective) & (Loss+ENS bjective) \\
\hline Power Losses $(\mathrm{kW})$ & 210.98 & 101.96 & 161.26 & 124.62 \\
ENS $(\mathrm{kWh} / \mathrm{yr})$ & 6.695 & 4.379 & 1.337 & 1.602 \\
Minimum Voltage $(\mathrm{pu})$ & 0.9130 & 0.9510 & 0.9466 & 0.9486 \\
Size and Location & -- & $2585 / 1 @ 29$ & $2097 / 1 @ 10$ & $2007 / 1 @ 30$ \\
Total Size $(\mathrm{kW})$ & -- & 2585 & 2097 & 2007 \\
Losses Cost $(\$ / \mathrm{yr})$ & 110891 & 53590.1 & 84761.3 & 65505.4 \\
Net Saving $(\$ / \mathrm{yr})$ & -- & 57300.9 & 26129.7 & 45385.6 \\
\hline
\end{tabular}


Table 8. Fuzzy multi-objective results for $1 \mathrm{WT}$ placement

\begin{tabular}{ccccc}
\hline & \multicolumn{4}{c}{ Maximum Size 3MW (kW/pf/@Bus) } \\
\cline { 2 - 4 } & No DG & $\begin{array}{c}\text { 1WT } \\
\text { (Loss objective) }\end{array}$ & $\begin{array}{c}\text { 1WT } \\
\text { (ENS objective) }\end{array}$ & $\begin{array}{c}\text { 1WT } \\
\text { (Loss+ENS objective) }\end{array}$ \\
\hline Power Losses $(\mathrm{kW})$ & 210.98 & 61.36 & 100.09 & 73.3816 \\
ENS $(\mathrm{kWh} / \mathrm{yr})$ & 6.695 & 4.406 & 0 & 1422.4586 \\
Minimum Voltage $(\mathrm{pu})$ & 0.9130 & 0.9667 & 0.9564 & 0.95677 \\
Size and Location & -- & $2544 / 0.8236 @ 6$ & $2639 / 0.8729 @ 7$ & $2078 / 0.833 @ 30$ \\
Total Size $(\mathrm{kW})$ & -- & 2544 & 2639 & 2078 \\
Losses Cost $(\$ / \mathrm{yr})$ & 110891 & 32253.1 & 52611.4 & 38569.3 \\
Net Saving $(\$ / \mathrm{yr})$ & -- & 78637.9 & 58279.6 & 72321.7 \\
\hline
\end{tabular}

Table 9. Fuzzy multi-objective results for $1 \mathrm{PV}$ and $1 \mathrm{WT}$ placement simultaneously

\begin{tabular}{ccccc}
\hline & \multicolumn{4}{c}{ Maximum Size 3MW (kW/pf/@ Bus) } \\
\cline { 2 - 5 } & No DG & $1 \mathrm{PV}$ & $1 \mathrm{WT}$ & $1 \mathrm{PV}+1 \mathrm{WT}$ \\
\hline Power Losses $(\mathrm{kW})$ & 210.98 & 124.6299 & 73.3816 & 38.3211 \\
ENS $(\mathrm{kWh} / \mathrm{yr})$ & 6.695 & 1.602 & 1.422 & 0.342 \\
Minimum Voltage $(\mathrm{pu})$ & 0.9130 & 0.9486 & 0.9567 & 0.9805 \\
Size and Location & -- & $2007 / 1 @ 30$ & $2078 / 0.833 @ 30$ & $873 / 1 @ 131405 / 0.8 @ 30$ \\
Total Size $(\mathrm{kW})$ & -- & 2007 & 2078 & 2278 \\
Losses Cost $(\$ / \mathrm{yr})$ & 110891 & 65505.4 & 38569.3 & 20141.5 \\
Net Saving $(\$ / \mathrm{yr})$ & -- & 45385.6 & 72321.7 & 90749.5 \\
\hline
\end{tabular}

\section{Conclusions}

In this paper, the new MOHTLBOGWO method was used to determine the location and capacity of solar panels and wind turbines for the purpose of reducing losses and improving reliability in the distribution network. The proposed problem was evaluated based on single-objective and multi-objective optimization based on fuzzy decision making in optimizing the use of renewable resources in the 33 Buses distribution network. The effectiveness of the proposed method in various optimizations was presented and compared with the MOTLBO and MOGWO results. The results showed that in the optimal placement of the solar panels and wind turbines, unlike their single-objective optimization, there is a compromised between the reduction of losses and improved reliability, and the optimal solution was determined from the set of answers of the Pareto levels. In comparison with the MOTLBO and MOGWO methods, the MOHTLBOGWO method has a better convergence in Pareto levels and achieves optimal solutions. Also, the ability of the proposed method in single-objective optimization In comparison with previous studies in reducing losses, improving the minimum voltage and increasing network profits was confirmed. The results also showed that the dispersal of renewable resources in the distribution network would result in more reduction of losses, greater improvement on reliability, and more financial gain on the network.

\section{References}

[1] H. Holttinen, P. Meibom, C. Ensslin, L. Hofmann, J. Mccann, and J. Pierik, Design and operation of power systems with large amounts of wind power, in VTT Research Notes 2493 (2009).

[2] C. A. Coello-Coello, An Introduction to Evolutionary MultiObjective Optimization with Some Applications in Pattern Recognition, in Iberoamerican Congress on Pattern Recognition (2014) 1-13.

[3] M. Hayerikhiyavi and A. Dimitrovski, Comprehensive Analysis of Continuously Variable Series Reactor Using GC Framework, arXiv preprint arXiv:2103.11136 (2021).
[4] P. Mehta, P. Bhatt, and V. Pandya, Optimal selection of distributed generating units and its placement for voltage stability enhancement and energy loss minimization, Ain Shams Engineering Journal 9 (2018) 187-201.

[5] S. Daud, A. Kadir, M. Lada, and C. Gan, A review: Optimal distributed generation planning and power quality issues, International Review of Electrical Engineering 11 (2016) 208.

[6] M. Jenkinson, P. Bannister, M. Brady, and S. Smith, Improved optimization for the robust and accurate linear registration and motion correction of brain images, Neuroimage 17 (2002) 825841.

[7] A. S. Zamzam, X. Fu, and N. D. Sidiropoulos, Data-driven learning-based optimization for distribution system state estimation, IEEE Transactions on Power Systems 34 (2019) 4796-4805.

[8] S. Golestani and M. Tadayon, Distributed generation dispatch optimization by artificial neural network trained by particle swarm optimization algorithm, in 2011 8th International Conference on the European Energy Market (EEM) (2011) 543548.

[9] H. Behbahani, S. M. Hosseini, A. Taherkhani, and H. Asadi, Safety Assessment on Merge and Diverge Areas using Fuzzy Inference System, Artificial Neural Network, and Particle Swarm Optimization, Computational Research Progress in Applied Science \& Engineering (CRPASE) 3 (2017).

[10] D. R. Prabha and T. Jayabarathi, Optimal placement and sizing of multiple distributed generating units in distribution networks by invasive weed optimization algorithm, Ain Shams Engineering Journal 7 (2016) 683-694.

[11] M. Yazdani, H. Musazadeh, H. A. Bagal, and A. Noruzi, Distribution Simultaneous Sizing, Sitting, and Service Area Determination of Sub-transmission Substations and Distributed Generations Considering Load Uncertainty by GSO Algorithm (2016).

[12] D. K. Khatod, V. Pant, and J. Sharma, Evolutionary programming based optimal placement of renewable distributed generators, IEEE Transactions on Power systems 28 (2012) 683695.

[13] D. Sattianadan, M. Sudhakaran, S. S. Dash, K. Vijayakumar, and P. Ravindran, Optimal placement of DG in distribution system using genetic algorithm, in International Conference on Swarm, Evolutionary, and Memetic Computing (2013) 639-647.

[14] M. Kaur and S. Ghosh, Effective Loss Minimization and Allocation of Unbalanced Distribution Network, Energies 10 (2017) 1931. 
[15] R. V. Rao, Teaching-learning-based optimization algorithm, in Teaching learning based optimization algorithm, ed: Springer (2016) 9-39.

[16] M. Gandomkar, M. Vakilian, and M. Ehsan, A combination of genetic algorithm and simulated annealing for optimal DG allocation in distribution networks, in Canadian Conference on Electrical and Computer Engineering (2005) 645-648.

[17] M. Tavana, M. Zareinejad, D. Di Caprio, and M. A. Kaviani, An integrated intuitionistic fuzzy AHP and SWOT method for outsourcing reverse logistics, Applied Soft Computing 40 (2016) 544-557.

[18] M. H. Moradi and M. Abedini, A combination of genetic algorithm and particle swarm optimization for optimal DG location and sizing in distribution systems, International Journal of Electrical Power \& Energy Systems 34 (2012) 66-74.

[19] Y. Shirai, F. Ueno, and T. Inoue, Configuration of fuzzy membership function circuits using current mode, Electronics and Communications in Japan (Part II: Electronics) 70 (1987) 59-67.

[20] H. Falaghi and M.-R. Haghifam, ACO based algorithm for distributed generation sources allocation and sizing in distribution systems, in 2007 IEEE Lausanne Power Tech (2007) 555-560.

[21] M. R. Shakarami and R. Sedaghati, A new approach for network reconfiguration problem in order to deviation bus voltage minimization with regard to probabilistic load model and DGs, Int J Electr Comput Energ Electr Commun Eng, 8 (2014) 430435.

[22] K. S. Rao and M. N. Rao, Optimal Placement of Multiple Distributed Generator by Hs Algorithm, planning, 2 (2012).

[23] M. Padma Lalitha, V. Veera Reddy, and N. Sivarami Reddy, Application of fuzzy and ABC algorithm for DG placement for minimum loss in radial distribution system, Iranian Journal of Electrical and Electronic Engineering 6 (2010) 248-257.

[24] M. Vosoogha and A. Addeh, An Intelligent Power Prediction Method for Wind Energy Generation Based on Optimized Fuzzy System, Computational Research Progress in Applied Science \& Engineering (CRPASE) 5 (2019) 34-43.

[25] M. J. Hadidian-Moghaddam, S. Arabi-Nowdeh, M. Bigdeli, and D. Azizian, A multi-objective optimal sizing and siting of distributed generation using ant lion optimization technique, Ain shams engineering journal 9 (2018) 2101-2109.

[26] S. Devi and M. Geethanjali, Application of modified bacterial foraging optimization algorithm for optimal placement and sizing of distributed generation, Expert Systems with Applications 41 (2014) 2772-2781.

[27] A. Soroudi and M. Ehsan, Imperialist competition algorithm for distributed generation connections, IET generation, transmission $\&$ distribution 6 (2012) 21-29.

[28] D. R. Prabha and T. Jayabarathi, Determining the optimal location and sizing of distributed generation unit using Plant Growth Simulation Algorithm in a radial distribution network, WSEAS Trans. Syst 13 (2014) 543-550.

[29] R. Rajaram, K. S. Kumar, and N. Rajasekar, Power system reconfiguration in a radial distribution network for reducing losses and to improve voltage profile using modified plant growth simulation algorithm with Distributed Generation (DG), Energy Reports 1 (2015) 116-122.

[30] M. Khatibi, F. Rahmani, and T. Agarwal, Comparative Analysis of Power System Model Reduction, arXiv preprint arXiv:2004.04112 (2020).

[31] K. Nadhir, D. Chabane, and B. Tarek, Firefly algorithm for optimal allocation and sizing of Distributed Generation in radial distribution system for loss minimization, in 2013 International Conference on Control, Decision and Information Technologies (CoDIT) (2013) 231-235.

[32] E. Ali, S. Abd Elazim, and A. Abdelaziz, Ant Lion Optimization Algorithm for optimal location and sizing of renewable distributed generations, Renewable Energy 101 (2017) 13111324.

[33] P. Reddy, V. Reddy, and T. G. Manohar, Ant lion optimization algorithm for optimal sizing of renewable, Electrical Power \& Energy Systems 28 (2017) 669-678.
[34] H. M. Hasanien and G. M. Hashem, A cuckoo search algorithm optimizer for steady-state analysis of self-excited induction generator, Ain Shams Engineering Journal 9 (2018) 2549-2555.

[35] J.-W. Choi and M.-K. Kim, Multi-objective optimization of voltage-stability based on congestion management for integrating wind power into the electricity market, Applied Sciences 7 (2017) 573.

[36] H. Shokouhandeh, M. Ghaharpour, H. G. Lamouki, Y. R. Pashakolaei, F. Rahmani, and M. H. Imani, Optimal Estimation of Capacity and Location of Wind, Solar and Fuel Cell Sources in Distribution Systems Considering Load Changes by Lightning Search Algorithm, in 2020 IEEE Texas Power and Energy Conference (TPEC), (2020) 1-6.

[37] R. V. Rao, V. J. Savsani, and D. Vakharia, Teaching-learningbased optimization: an optimization method for continuous nonlinear large scale problems, Information sciences 183 (2012) 115.

[38] S. Mirjalili, S. M. Mirjalili, and A. Lewis, Grey wolf optimizer, Advances in engineering software 69 (2014) 46-61.

[39] P. Reddy and D. Prasad, Application of loss sensitivity factor and genetic algorithm for capacitor placement for minimum loss in radial distribution system, International Journal of Engineering Sciences \& Research Technology 9 (2013) 2400-2403.

[40] M. Asadi, H. Shokouhandeh, F. Rahmani, S. M. Hamzehnia, M. N. Harikandeh, H. G. Lamouki, et al., Optimal placement and sizing of capacitor banks in harmonic polluted distribution network, in 2021 IEEE Texas Power and Energy Conference (TPEC) (2021) 1-6.

[41] J. Sardi, N. Mithulananthan, and D. Q. Hung, A loss sensitivity factor method for locating ES in a distribution system with PV units, in 2015 IEEE PES Asia-Pacific Power and Energy Engineering Conference (APPEEC) (2015) 1-5.

[42] H. Haggi, S. R. Marjani, and M. A. Golkar, The effect of rescheduling power plants and optimal allocation of STATCOM in order to Improve power system static security using TLBO algorithm, in 2017 Iranian Conference on Electrical Engineering (ICEE) (2017) 1120-1125.

[43] N. Sabpayakom and S. Sirisumrannukul, Power losses reduction and reliability improvement in distribution system with Very Small Power Producers, Energy Procedia 100 (2016) 388-395.

[44] H. Haggi, W. Sun, and J. Qi, Multi-Objective PMU Allocation for Resilient Power System Monitoring, in 2020 IEEE Power \& Energy Society General Meeting (PESGM) (2020) 1-5.

[45] C. E. Robles-Rodriguez, C. Bideaux, S. E. Guillouet, N. Gorret, G. Roux, C. Molina-Jouve, et al., Multi-objective particle swarm optimization (MOPSO) of lipid accumulation in Fed-batch cultures, in 2016 24th Mediterranean Conference on Control and Automation (MED) (2016) 979-984.

[46] A. Taghavirashidizadeh, R. Parsibenehkohal, M. Hayerikhiyavi, and M. Zahedi, A Genetic algorithm for multi-objective reconfiguration of balanced and unbalanced distribution systems in fuzzy framework, Journal of Critical Reviews 7 (2020) 639343.

[47] R. Etemad, M. S. Ghazizadeh, and M. Ahmadian, Exploiting end-users capability in voltage support by means of power electronic transformer, International Transactions on Electrical Energy Systems 27 (2017) e2406. 